\title{
Hepatic nuclear factor kappa B signaling pathway and NLR family pyrin domain containing 3 inflammasome is over-activated in ketotic dairy cows
}

\author{
Taiyu Shen, ${ }^{1 *}$ Xinwei Li, ${ }^{1 *}$ Juan J. Loor, ${ }^{2}$ Yiwei Zhu, ${ }^{1}$ Xiliang Du, ${ }^{1}$ Xinghui Wang, ${ }^{1}$ Dongmei Xing, ${ }^{3}$ Zhen Shi, ${ }^{1}$ \\ Zhiyuan Fang, ${ }^{1}$ Xiaobing $\mathrm{Li}^{1}{ }^{1}$ and Guowen $\mathrm{Liu}^{1} \dagger$ \\ ${ }^{1}$ Key Laboratory of Zoonoses Research, Ministry of Education, College of Veterinary Medicine, Jilin University, 5333 Xi'an Road, Changchun, \\ Jilin Province, 130062, China \\ ${ }^{2}$ Mammalian NutriPhysioGenomics, Department of Animal Sciences and Division of Nutritional Sciences, University of Illinois, Urbana 61801 \\ ${ }^{3}$ Animal Medicine College, Hunan Agriculture University, Changsha, Hunan, 410128, China
}

\section{ABSTRACT}

Ketosis is an important metabolic disease that can negatively affect the production efficiency of dairy cows. Earlier studies have revealed metabolic and inflammatory alterations in the blood associated with ketosis; however, a link between ketosis and hepatic inflammation has not been well documented. The objective of this study was to investigate whether the nuclear factor kappa B (NF- $\kappa \mathrm{B})$ signaling pathway and NLR family pyrin domain containing 3 (NLRP3) inflammasome were activated in the liver of ketotic cows. Liver and blood samples were collected from healthy $(\mathrm{n}=$ 15 , control group) and ketotic $(\mathrm{n}=15$, ketosis group) cows that had a similar number of lactations (median $=3$, range $=2$ to 4 ) and days in milk (median $=6 \mathrm{~d}$, range $=3$ to $9 \mathrm{~d}$ ). Results showed that serum levels of fatty acids, $\beta$-hydroxybutyrate (BHB), aspartate aminotransferase (AST), and alanine aminotransferase (ALT) were higher and glucose was lower in ketotic cows. Concentrations of serum proinflammatory cytokines IL18, tumor necrosis factor (TNF)- $\alpha$, and IL1B were greater and the anti-inflammatory cytokine IL10 was lower in the ketosis group. Cows with ketosis had triacylglycerol accumulation in the liver. Upregulation of phosphorylated (p)-NF- $\kappa \mathrm{B}$ and p-inhibitor of $\kappa \mathrm{B}(\mathrm{I} \kappa \mathrm{B}) \alpha$ protein abundance in cows with ketosis indicated that the hepatic NF- $\kappa \mathrm{B}$ signaling pathway was overactivated. The mRNA abundance of TNFA, inducible nitric oxide synthase (NOS2), IL18, and $I L 1 B$ were greater and $I L 10$ was lower in ketotic cows. More importantly, the mRNA and protein abundance of NLRP3 and caspase-1 (CASP1) along with CASP1 activity were greater in the liver of cows with ketosis.

Received March 29, 2019.

Accepted July 3, 2019.

*These authors contributed equally to this work.

†Corresponding author: liuguowen2008@163.com
Overall, the data indicate that the onset of ketosis is accompanied by activation of the NF- $\kappa \mathrm{B}$ signaling pathway and NLRP3 inflammasome, resulting in a state of inflammation.

Key words: ketosis, inflammation, nuclear factor$\mathrm{kB}$ signaling, NLR family pyrin domain containing 3 inflammasome (NLRP3) inflammasome

\section{INTRODUCTION}

During the transition from late gestation to early lactation, the vast majority of high-yielding cows suffer from metabolic stress resulting in large part from negative energy balance (Loor et al., 2013; Xu et al., 2016). Mobilization of adipose tissue due to negative energy balance leads to fatty acid release into blood and uptake primarily by the liver (Yang et al., 2018). A large portion of fatty acids in the liver are incompletely oxidized to ketone bodies, with BHB and acetoacetic acid being the most quantitatively important. Excessive ketone body accumulation in the blood leads to the onset of ketosis (Zhang et al., 2018), a disorder that occurs with high frequency during the transition period (Shi et al., 2015). Recent data revealed that serum concentrations of inflammatory biomarkers including haptoglobin, serum amyloid A, and tumor necrosis factor (TNF)- $\alpha$ were elevated in ketotic cows (Abuajamieh et al., 2016; El-Deeb and El-Bahr, 2017). Thus, systemic inflammation seems to be another feature of the ketotic state. Whether tissues such as the liver experience a state of inflammation during ketosis is not well known.

Nuclear factor kappa B (NF- $\mathbf{B}$ ) is known for its function in immunity, inflammation, and metabolic diseases (Taniguchi and Karin, 2018). In its inactive form, NF- $\kappa \mathrm{B}$ is sequestered in the cytoplasm bound to the inhibitor of $\kappa \mathrm{B}$ (I $\kappa \mathrm{B})$, whose phosphorylation is dependent on the activity of an inhibitor of $\kappa \mathrm{B}$ kinase (IKK $\boldsymbol{\beta}$, Oeckinghaus et al., 2011). Once stimulated, NF- $\kappa \mathrm{B}$ unit p65 separates from I $\kappa \mathrm{B}$ and translocates into the nucleus, where NF- $\kappa \mathrm{B}$ can regulate the tran- 
scription of several inflammatory genes such as TNFA and pro-interleukin $I L 1 B$ (Taniguchi and Karin, 2018; Cui et al., 2019). High-fat feeding in mice and nonalcoholic fatty liver disease (NAFLD) in humans are associated with overactivation of the NF- $\kappa \mathrm{B}$ signaling pathway in the liver (Arkan et al., 2005; Cai et al., 2005; Farrell and Larter, 2006). We recently demonstrated that a high concentration of fatty acids activated NF$\kappa \mathrm{B}$ signaling and induced lipid accumulation in dairy cow hepatocytes (Li et al., 2015). These data indicate that activation of $\mathrm{NF}-\kappa \mathrm{B}$ signaling might aggravate hepatic lipid metabolism in ketotic conditions but the activity of this pathway has not been evaluated in cows with ketosis.

The activation of NF- $\kappa \mathrm{B}$ not only upregulates numerous inflammatory cytokines and cytokine precursors but also primes NLR family pyrin domain containing 3 (NLRP3), which is important for inflammasome activation (Zhong et al., 2016). The NLRP3 inflammasome contains NOD-like receptor NLRP3, the adaptor molecule apoptosis-associated speck-like protein containing CARD (ASC), and the effector molecule pro-caspase-1 (pro-CASP1, Meng et al., 2019). An increase in hepatic NLRP3 inflammasome activation was detected in mice and humans with metabolic disorders such as type 2 diabetes mellitus, NAFLD, and obesity (De Nardo and Latz, 2011; Stienstra et al., 2011; Vandanmagsar et al., 2011). Inhibition of the NLRP3 inflammasome in mice fed a high-fat diet prevented the development of NAFLD (Yang et al., 2016). Together, these studies demonstrate that NLRP3 inflammasome activation is involved in the development of disorders of hepatic lipid metabolism. Whether the NLRP3 inflammasome is associated with ketosis in dairy cows is unknown.

Because of the high prevalence of ketosis in periparturient cows and given the role of NF- $\mathrm{KB}$ signaling and NLRP3 inflammasome in hepatic metabolism, the objective of this study was to investigate the activation status of these pathways via mRNA and protein abundance analyses of liver tissue from healthy and ketotic cows.

\section{MATERIALS AND METHODS}

\section{Animals}

Use of cows in this study was approved by the Ethics Committee on the Use and Care of Animals of Jilin University (Changchun, China, 2017; clinical trial 201711039). The cows in the present study underwent a thorough clinical examination by the same veterinarian to ensure that the cows had no comorbidities with ketosis. All of the cows were housed in a tiestall barn and offered a TMR at 0700 and $1330 \mathrm{~h}$ daily for ad libitum intake, with free access to tap water. The basal diet formulation is given in Supplemental Table S1 (https: //doi.org/10.3168/jds.2019-16706). Cows with similar numbers of lactations (median $=3$, range $=2$ to 4 ) and DIM (median $=6 \mathrm{~d}$, range $=3$ to $9 \mathrm{~d}$ ) were selected from a 1,000-cow dairy farm located in Changchun, Jilin Province, China. Cows were preliminarily classified based on the degree of feed intake, milk yield, and positive ketone bodies in milk, as assessed by the nitroprusside test. Subsequently, the blood concentration of BHB was measured in order to select cows for further work. According to clinical symptoms and BHB level in the serum, 15 cows with serum BHB content $>3 \mathrm{~m} M$ were classified as ketotic and 15 cows with serum BHB content $<1.2 \mathrm{~m} M$ were classified as healthy (McArt et al., 2012; Vanholder et al., 2015). The basic description of the cows used is shown in Table 1.

\section{Sample Collection}

Milk yield was recorded on 3 consecutive days at 0530 and $1500 \mathrm{~h}$. Milk samples $(50 \mathrm{~mL})$ were collected

Table 1. Basic description of the control and ketotic cows; data were analyzed using Wilcoxon signed-rank test and expressed as mean $\pm \mathrm{SEM}$

\begin{tabular}{|c|c|c|c|}
\hline Item & Control $(\mathrm{n}=15)$ & Ketosis $(\mathrm{n}=15)$ & $P$-value \\
\hline BW (kg) & $637.53 \pm 6.52$ & $678.50 \pm 6.84$ & 0.0001 \\
\hline $\mathrm{BCS}$ & $2.87 \pm 0.03$ & $3.18 \pm 0.08$ & $<0.0001$ \\
\hline Milk yield (kg) & $30.80 \pm 0.34$ & $24.62 \pm 0.35$ & $<0.0001$ \\
\hline DMI (kg) & $22.40 \pm 0.39$ & $19.24 \pm 0.29$ & $<0.0001$ \\
\hline BHB $(\mathrm{m} M)$ & $0.35 \pm 0.01$ & $3.49 \pm 0.11$ & $<0.0001$ \\
\hline Fatty acids $(\mathrm{m} M)$ & $0.29 \pm 0.02$ & $1.19 \pm 0.06$ & $<0.0001$ \\
\hline Glucose $(\mathrm{m} M)$ & $4.03 \pm 0.07$ & $2.23 \pm 0.03$ & $<0.0001$ \\
\hline $\mathrm{AST}^{1}(\mathrm{U} / \mathrm{L})$ & $72.00 \pm 1.59$ & $156.40 \pm 3.52$ & $<0.0001$ \\
\hline $\operatorname{ALT}^{1}(\mathrm{U} / \mathrm{L})$ & $18.80 \pm 1.18$ & $35.53 \pm 1.87$ & $<0.0001$ \\
\hline Milk fat (\%) & $3.41 \pm 0.23$ & $4.13 \pm 0.21$ & 0.006 \\
\hline Milk protein (\%) & $3.31 \pm 0.08$ & $2.90 \pm 0.07$ & $<0.0001$ \\
\hline Milk lactose (\%) & $5.08 \pm 0.08$ & $4.64 \pm 0.18$ & 0.039 \\
\hline
\end{tabular}

${ }^{1} \mathrm{AST}=$ aspartate aminotransferase; ALT $=$ alanine aminotransferase. 
at each milking from each cow on 3 consecutive days, and then stored at $4^{\circ} \mathrm{C}$ with preservative $(1 \mathrm{mg} / \mathrm{mL}$ of potassium dichromate) until analyzed for milk composition by using an infrared analyzer with a 4-channel spectrophotometer (Sun et al., 2019; Foss MilkoScan, Foss Food Technology Co., Eden Prairie, MN). Blood samples were collected between 0700 and $0900 \mathrm{~h}$ (before the morning feeding) from a coccygeal vein and immediately centrifuged at $3,500 \times g$ for $15 \mathrm{~min}$ at $4^{\circ} \mathrm{C}$. Serum was obtained and stored at $-80^{\circ} \mathrm{C}$ until analysis. Liver tissue samples were taken from the 11th or 12 th right intercostal space by liver puncture needle (Shanghai Surgical Equipment Factory, Shanghai, China) after blood collection. The intercostal space was shaved before the liver biopsy, sanitized with iodine scrub and $75 \%$ alcohol, and anesthetized with a subcutaneous injection of $2 \%$ lidocaine $\mathrm{HCl}$ (Sigma-Aldrich Co., St. Louis, MO). A scalpel blade was used to make a $3-\mathrm{mm}$ stab incision in the skin. The puncture needle was then inserted through the intercostal muscle and into the liver. The liver tissue biopsies $(\sim 200 \mathrm{mg})$ were immediately frozen in liquid nitrogen or fixed with $4 \%$ paraformaldehyde or OCT compound (4583; Sakura Finetek Co., Torrance, CA).

\section{Determination of Blood Parameters}

Serum concentrations of glucose, BHB, and fatty acids were determined using a Hitachi 7170 autoanalyzer (Hitachi, Tokyo, Japan) with commercially available kits (BHB: cat. no. RB1008; fatty acids: cat. no. FA115; glucose: cat. no. GL3815; Randox Laboratories, Crumlin, UK). The activities of aspartate aminotransferase (AST), and alanine aminotransferase (ALT) were determined using an automatic biochemistry analyzer (Sekisui Medical Co. Ltd., Tokyo, Japan) with commercially available kits (AST: AS3804; ALT: AL3801; Randox Laboratories).

\section{ELISA}

The concentrations of TNF- $\alpha$, IL18, IL1B, and IL10 were assessed with the following commercially available ELISA kits: Bovine TNF- $\alpha$ (Brodzki et al., 2019, SEA133Bo; USCN Life Science Inc., Wuhan, China); Bovine IL18 ELISA kit (SEA064Bo; USCN Life Science Inc.), IL1B ELISA kit (SEA563Bo; USCN Life Science Inc.), and IL10 ELISA kit (Brodzki et al., 2019, SEA056Bo; USCN Life Science Inc.) according to the manufacturer's instructions. The intra- and interassay coefficients of variation for all of the examined cytokines were $<10$ and $12 \%$, respectively. The analyzed sensitivity of TNF- $\alpha$, IL10, IL1B, and IL18 was less than $3.1,6.4,6.5$, and $6.3 \mathrm{pg} / \mathrm{mL}$, respectively. Every serum sample was analyzed in triplicate, and absorbance values were read at $450 \mathrm{~nm}$ using a spectrophotometer (51119100; Thermo Fisher Scientific, Shanghai, China).

\section{Liver Histology}

Liver tissue was fixed in 10\% formaldehyde neutral buffer solution, embedded in paraffin, and cut into $8-\mu \mathrm{m}$ slices, floated on a water bath, picked up onto glass slides, and placed in slide racks. Slides were dewaxed with xylene, rehydrated through descending concentrations of alcohol, and stained with hematoxylin and eosin (H\&E).

For Oil-red O staining, liver tissue was frozen in OCT compound (4583; Sakura Finetek Co.), sectioned into $8-\mu \mathrm{m}$ slices at $-18^{\circ} \mathrm{C}$, and fixed with $75 \%$ alcohol at room temperature for $15 \mathrm{~min}$. Next, slides were stained with Oil red O (O0625; Sigma-Aldrich Co.) and counterstained with hematoxylin. Representative photomicrographs were captured at $400 \times$ magnification using a system incorporated in the microscope.

\section{Triacylglycerol Content Determination}

Liver tissue $(\sim 20 \mathrm{mg})$ was homogenized with lysate provided by the Applygen Kit (E1013; Applygen Technologies Inc., Beijing, China). A portion of the supernatant was used to determine total protein concentration using the bicinchoninic acid (BCA) assay (P1511; Applygen Technologies Inc.). The remaining supernatant was heated in a water bath $\left(70^{\circ} \mathrm{C}\right)$ for 10 min. After cooling the samples at room temperature, they were vortexed and centrifuged at 2,000 $\times g$ for 5 min at $4^{\circ} \mathrm{C}$. The supernatant was collected and used for a triacylglycerol (TG) assay using an enzymatic kit (E1013; Applygen Technologies Inc.) following the manufacturer's instructions.

\section{Western Blotting}

Liver tissue $(\sim 20 \mathrm{mg})$ was lysed in ice-cold RIPA lysis buffer (C1053; Applygen Technologies Inc.) for $30 \mathrm{~min}$ before centrifugation at $12,000 \times g$ for $15 \mathrm{~min}$ at $4^{\circ} \mathrm{C}$. The supernatant was collected and the protein concentrations were quantified using the BCA Protein Assay Kit (P1511; Applygen Technologies Inc.). Forty micrograms of protein was separated by $10 \%$ or $12 \%$ SDS-PAGE and then electrophoretically transferred onto polyvinylidene fluoride membranes, which were blocked for $4 \mathrm{~h}$ at room temperature with $3 \%$ BSA/ Tris-buffered saline (TBS)-Tween buffer. The blocked membranes were incubated overnight at $4^{\circ} \mathrm{C}$ with di-

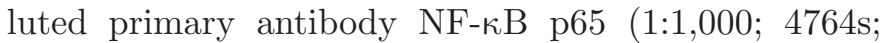
Cell Signaling Technology Inc., Danvers, MA), phos- 


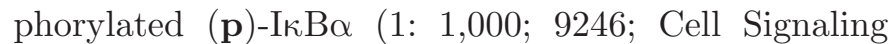

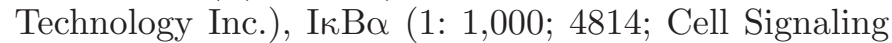
Technology Inc.), p-NF-кB p65 (1: 2,000; ab86299; Abcam, Cambridge, MA), NLRP3 (1: 1,000; ab210491; Abcam), CASP1 (1: 5,000; ab201476; Abcam), and $\beta$-actin (1: 2,000; ab8226; Abcam). After washing 4 times with TBS containing $0.1 \%$ Tween 20 for $7 \mathrm{~min}$ at room temperature with shaking, the membranes were incubated with the appropriate peroxidase-conjugated secondary antibody for 45 min at room temperature with shaking, and then washed 4 times for $7 \mathrm{~min}$. The immunoreactive bands were visualized by enhanced chemiluminescence (ECL, WBKLS0500; Millipore, Bedford, MA). All bands were quantified by using Image-Pro Plus (Media Cybernetics Inc., Rockville, $\mathrm{MD})$. In this study, $\beta$-actin used as a reference protein, the phosphorylation level of NF- $\kappa \mathrm{B}$ was calculated as p-NF- $\kappa \mathrm{B} /$ total NF- $\kappa \mathrm{B}$, and the phosphorylation level of $\mathrm{I} \kappa \mathrm{B} \alpha$ was calculated as $\mathrm{p}-\mathrm{I} \kappa \mathrm{B} \alpha / \beta$-actin.

\section{Quantitative Real-Time PCR Analysis}

Total RNA was extracted from liver tissue using RNAiso Plus (9109; TaKaRa Biotechnology Co. Ltd., Dalian, China) according to the manufacturer's instruction, and then quantified using a K5500 MicroSpectrophotometer (Beijing Kaiao Technology Development Ltd., Beijing, China) and by electrophoresis (1\% agarose gels). Complementary (c)DNA was generated from total RNA using a reverse transcription kit (RR047A; TaKaRa Biotechnology Co. Ltd.) accord- ing to the manufacturer's instructions. We evaluated mRNA expression levels using quantitative real-time (qRT)-PCR technology with the SYBR Green QuantiTect RT-PCR Kit (RR420A; TaKaRa Biotechnology Co. Ltd.) and a 7500 Real-Time PCR System (Applied Biosystems Inc., Waltham, MA). The qRT-PCR was conducted with an initial denaturation at $94^{\circ} \mathrm{C}$ for 2 min, 35 cycles of amplification (denaturation at $94^{\circ} \mathrm{C}$ for $10 \mathrm{~s}$, annealing at $60^{\circ} \mathrm{C}$ for $15 \mathrm{~s}$, and extension at $72^{\circ} \mathrm{C}$ for $30 \mathrm{~s}$ ), and extension at $72^{\circ} \mathrm{C}$ for $5 \mathrm{~min}$. The PCR efficiency (E) and correlation coefficient $\left(\mathrm{R}^{2}\right)$ were calculated by the slope of the standard curves of using serial 10-fold dilutions of sample cDNA. [Note that when calculating the PCR amplification efficiency, $\mathrm{R}^{2}$ represents the correlation coefficient (Bustin et al., 2009). Therefore, $\mathrm{R}^{2}$ is the correlation coefficient in this study.] The efficiency was calculated as follows: E $(\%)=\left(10^{-1 / \text { slope }}-1\right) \times 100$ (Kubista et al., 2006). We calculated the relative gene expression by using a mathematical model, which includes an efficiency correction for PCR efficiency (Pfaffl, 2001). The relative expression of each target gene was normalized to 2 reference genes, $A C T B$ and GAPDH. The qRT-PCR reaction was performed in triplicate for each of the 15 cows per group. The primers pairs used in this study are listed in Table 2; $A C T B$ and GAPDH were stably expressed in different groups (Supplemental Figure S1, https:// doi.org/10.3168/jds.2019-16706; Komatsu et al., 2005; Graber et al., 2010; Du et al., 2018a). The efficiency of primers used is given in Supplemental Table S2 (https: //doi.org/10.3168/jds.2019-16706).

Table 2. Primer sequences (For, forward; Rev, reverse)

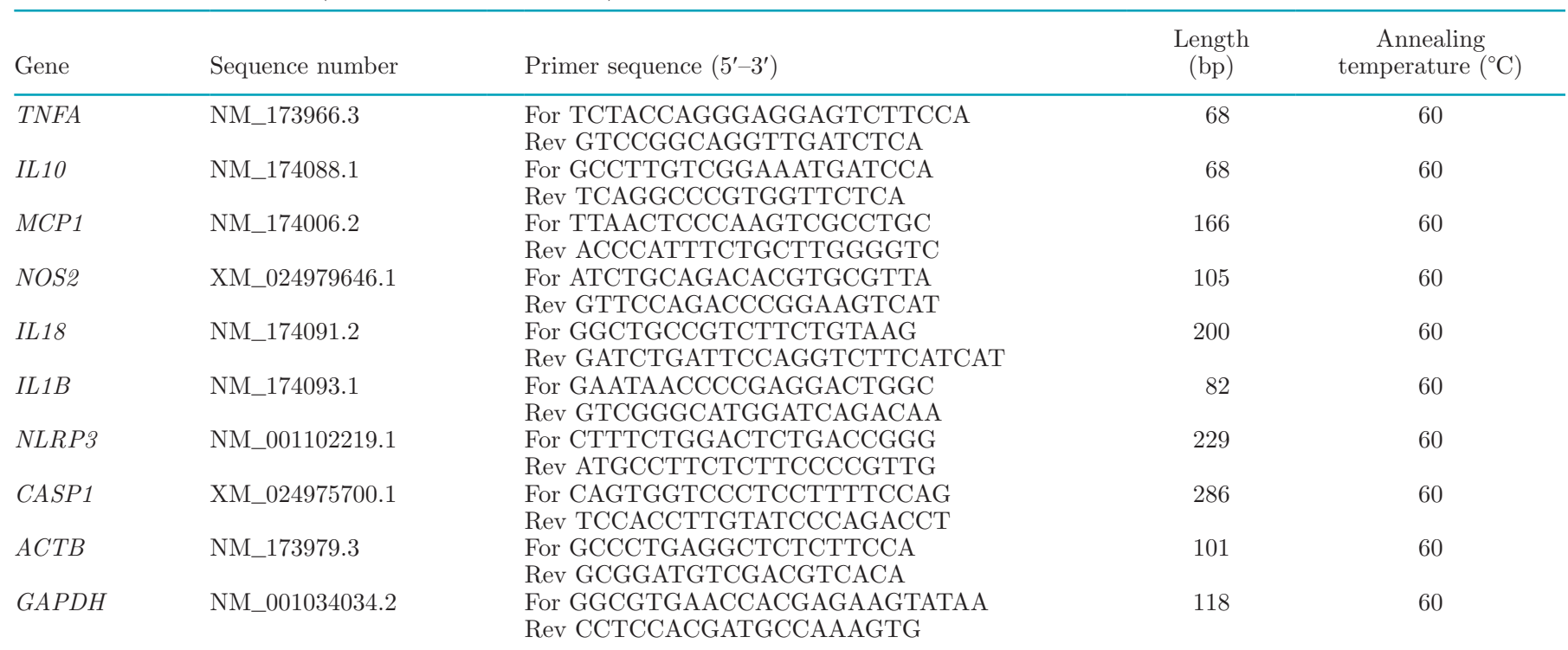

${ }^{1} T N F A$, tumor necrosis factor- $\alpha$; IL10, interleukin-10; MCP1, chemokine monocyte chemoattractant protein-1; NOS2, nitric oxide synthase; $I L 18$, interleukin-18; IL1B, interleukin-1B; NLRP3, NLR family pyrin domain containing 3 inflammasome; CASP1, caspase-1; ACTB, $\beta$-actin. 


\section{CASP1 Activity Determination}

The enzymatic activity of CASP1 was assayed using a CASP1 Activity Kit according to the manufacturer's protocol (C1102; Beyotime Institute of Biotechnology, Beijing, China). Briefly, liver tissue was homogenized in lysis buffer and centrifuged for $15 \mathrm{~min}$ at $16,000 \times \mathrm{g}$ at $4^{\circ} \mathrm{C}$. The supernatant was collected, and protein concentration determined by using the Bradford Protein Assay Kit (P0006; Beyotime Institute of Biotechnology). A volume of $50 \mu \mathrm{L}$ of tissue extract (containing $30 \mu \mathrm{g}$ of protein) was incubated in a 96-well plate with reaction buffer and acetyl-tyrosyl-valyl-alanyl-aspartic acid p-nitroanilide (Ac-YVAD- $\rho \mathrm{NA}$ ) for $2 \mathrm{~h}$ at $37^{\circ} \mathrm{C}$. The absorbance values of $\rho$-nitroaniline $(\rho \mathrm{NA})$ at 405 $\mathrm{nm}$ were measured using a 96-well plate reader, recorded every $1 \mathrm{~min}$ for 5 consecutive min (51119100; Thermo Fisher Scientific). One unit is the amount of enzyme that will cleave $1.0 \mathrm{nmol}$ of the colorimetric substrate Ac-YVAD- $\rho \mathrm{NA}$ per hour at $37^{\circ} \mathrm{C}$ under saturated substrate concentrations.

\section{IKK $\beta$ Activity Determination}

The IKK $\beta$ activity in the tissue extracts was measured using an IKK $\beta$ Kinase Assay Kit (GMS50162.4; GenMed Scientifics Inc., Wilmington, DE) according to the manufacturer's instructions. Briefly, liver tissue ( $\sim 20 \mathrm{mg})$ was washed in pre-cold GenMed clean buffer (reagent A) and homogenized in an ice bath with lysis buffer (reagent B). After fully mixing, samples were incubated in an ice bath for $30 \mathrm{~min}$. Then, the samples were centrifuged for $10 \mathrm{~min}$ at $10,000 \times g$ at $4^{\circ} \mathrm{C}$. The supernatant was collected and the protein concentrations were determined using the BCA Protein Assay Kit (P1511; Applygen Technologies Inc.). Total IKK $\beta$ activity was measured as follows: $130 \mu \mathrm{L}$ of GenMed buffer (reagent C), $20 \mu \mathrm{L}$ of GenMed enzymatic solution (reagent D), $20 \mu \mathrm{L}$ of GenMed reaction solution (reagent E), and $20 \mu \mathrm{L}$ of GenMed substrate (reagent F) were combined into a 96-well plate followed by incubation at $30^{\circ} \mathrm{C}$ for $3 \mathrm{~min}$; then, $10 \mu \mathrm{L}$ of GenMed negative solution (reagent $\mathrm{G}$ ) or sample was added, and absorbance values were read immediately at $450 \mathrm{~nm}$ using a spectrophotometer (51119100; Thermo Fisher Scientific). The nonspecific IKK $\beta$ activity was measured as follows: $20 \mu \mathrm{L}$ of reagent $\mathrm{C}$ in a $1.5-\mathrm{mL}$ centrifuge tube was combined with $10 \mu \mathrm{L}$ of GenMed reagent $\mathrm{H}$ and sample and then incubated at $30^{\circ} \mathrm{C}$ for $30 \mathrm{~min}$. Then, $100 \mu \mathrm{L}$ of reagent $\mathrm{C}, 20 \mu \mathrm{L}$ of reagent $\mathrm{D}, 20 \mu \mathrm{L}$ of reagent $\mathrm{E}$, and $20 \mu \mathrm{L}$ of reagent $\mathrm{F}$ were combined in a 96-well plate and incubated at $30^{\circ} \mathrm{C}$ for $3 \mathrm{~min}$. Last, each sample was aliquotted into a corresponding well and absorbance was read immediately at $450 \mathrm{~nm}$ using a spectrophotometer (51119100; Thermo Fisher Scientific). The specific IKK $\beta$ activity was calculated as total IKK $\beta$ activity - nonspecific IKK $\beta$ activity.

\section{Statistical Analysis}

Data from Western blotting and qRT-PCR were normally distributed and analyzed with paired $t$-tests; other data were non-normally distributed and analyzed using the Wilcoxon signed-rank test. All analyses were performed using GraphPad Prism 5.0 (Graph Pad Software, San Diego, CA) or SPSS 23.0 software (IBM Corp., Armonk, NY). Data are expressed as the mean \pm standard errors of the mean; $P<0.05$ was considered statistically significant, and $P<0.01$ was considered highly significant.

\section{RESULTS}

\section{Blood Parameters}

As shown in Table 1 , BW $(P<0.01)$ and BCS $(P<$ $0.01)$ were greater and DMI $(P<0.01)$ and milk yield were lower $(P<0.01)$ in cows with ketosis than in control cows. Blood concentrations of fatty acids and BHB and serum activities of ALT and AST were all greater $(P<0.01)$ in cows with ketosis. Milk protein $(P$ $<0.01)$ and milk lactose $(P<0.05)$ contents were both lower in the cows with ketosis, and milk fat content was higher $(P<0.01)$ in the ketotic cows.

\section{Liver TG Content}

Data from $\mathrm{H} \& \mathrm{E}$ and Oil-red $\mathrm{O}$ staining indicated greater lipid accumulation in cows with ketosis. A considerable mass of fat vacuoles was detected in the liver of ketotic cows (Figure 1A), in accordance with the greater $(P<0.01)$ hepatic TG content (Figure 1B).

\section{Systemic Inflammation Biomarkers}

The serum levels of TNF- $\alpha(P<0.01)$, IL18 $(P<$ $0.05)$, and IL1B $(P<0.01)$ were all greater (Figure $2 \mathrm{~A}$, $\mathrm{B}$ and $\mathrm{C})$, and concentration of IL10 lower $(P<0.01)$ in ketotic cows (Figure 2D).

\section{Activation of NF-KB Signaling in the Liver}

Hepatic activity of $\operatorname{IKK} \beta(P<0.01)$ and abundance

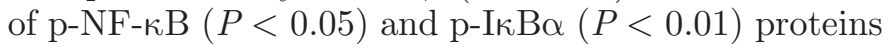
were greater in cows with ketosis (Figure $3 \mathrm{~A}, \mathrm{~B}$, and $\mathrm{C}$ ). Furthermore, hepatic mRNA abundance of proinflammatory factors TNFA, NOS2, and chemokine monocyte chemoattractant protein-1 $(M C P 1)$ was all greater $(P$ 

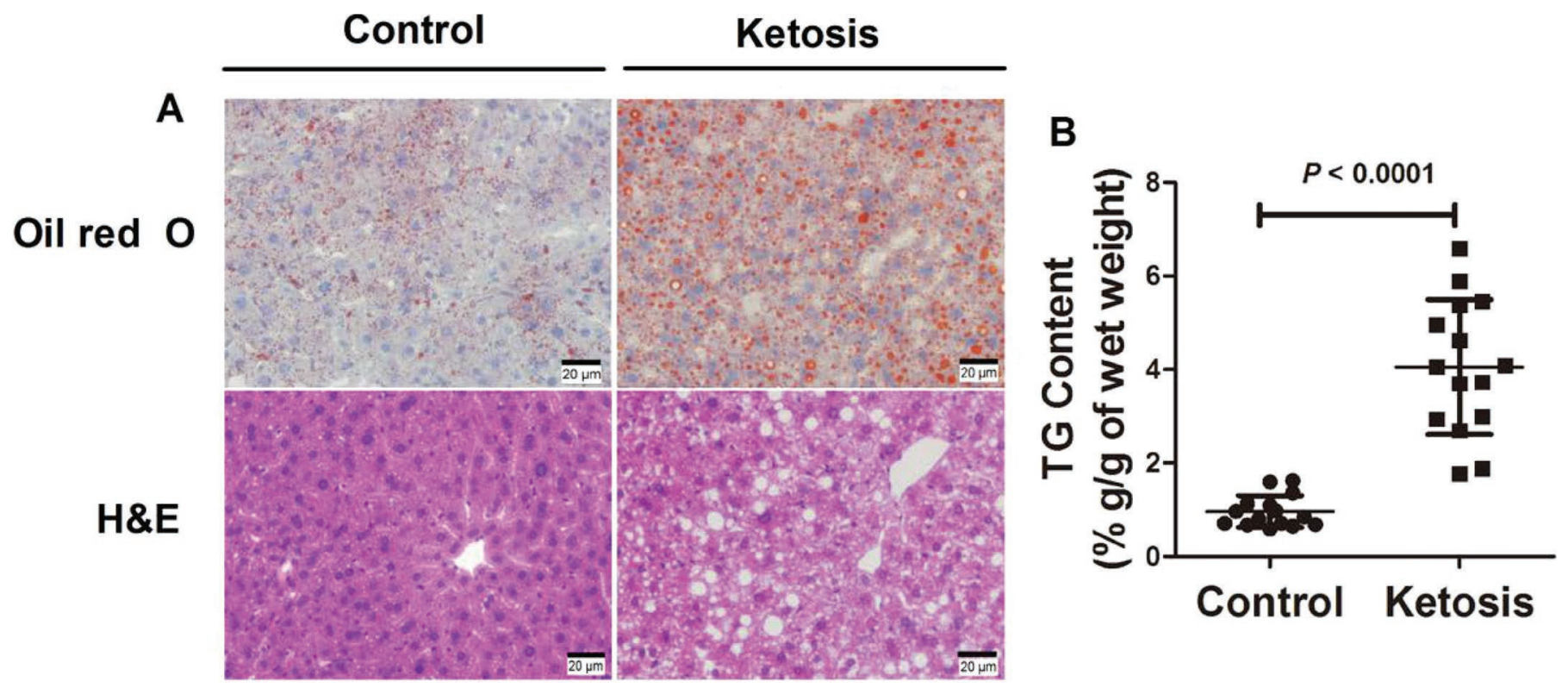

Figure 1. Liver histology and triglyceride (TG) content. (A) Representative images of hematoxylin and eosin (H\&E; original magnification $400 \times$; scale bar $20 \mu \mathrm{m}$ ) and Oil-red O (original magnification $400 \times$; scale bar $20 \mu \mathrm{m}$ ) staining of liver sections. (B) Hepatic TG content in control cows $(\mathrm{n}=15)$ and dairy cows with ketosis $(\mathrm{n}=15)$; TG contents were non-normally distributed and analyzed with Wilcoxon signed-rank test. Data were expressed as the mean \pm SEM.

$<0.01$ ) in cows with ketosis (Figure 4A, B, and C). The mRNA abundance of hepatic anti-inflammatory factor $I L 10$ was lower $(P<0.01)$ in cows with ketosis (Figure 4D).
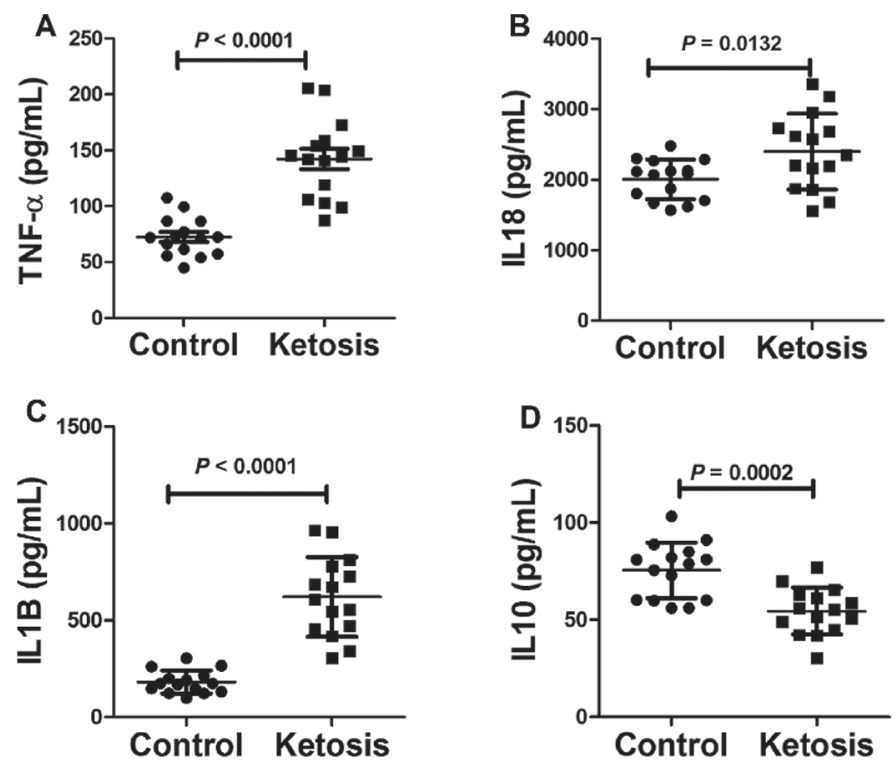

Figure 2. Serum concentrations of pro-inflammatory cytokines tumor necrosis factor (TNF)- $\alpha$ (A), IL18 (B), and IL1B (C), and antiinflammatory cytokine IL10 (D) in ketotic $(\mathrm{n}=15)$ and control $(\mathrm{n}$ $=15$ ) cows. Data were non-normally distributed and analyzed with Wilcoxon signed-rank test. Data were expressed as the mean \pm SEM.

\section{Activation of Hepatic NLRP3 Inflammasome}

The protein abundance of NLRP3 and CASP1 (Figure $5 \mathrm{~A}, \mathrm{~B})$ along with mRNA abundance of NLRP3, $C A S P 1, I L 18$, and $I L 1 B$ were all greater $(P<0.01)$ in cows with ketosis (Figure $5 \mathrm{C}$ ). Furthermore, the activity of CASP1 in the liver of cows with ketosis was greater $(P<0.01$, Figure $5 \mathrm{D})$.

\section{DISCUSSION}

Periparturient dairy cows experience sudden changes in diet, metabolic, and immune responses, all of which render them susceptible to metabolic disorders such as fatty liver and ketosis (Bobe et al., 2004; Xu et al., 2015; Du et al., 2018b). Ketotic cows often display high blood concentrations of fatty acids and BHB (Deng et al., 2015). High levels of fatty acids and BHB can induce lipotoxicity (Shi et al., 2014; Song et al., 2014; Deng et al., 2015) and, at least in nonruminants, lead to metabolic dysfunction, cell death, and chronic inflammation (Ertunc and Hotamisligil, 2016). In human and mouse, metabolic disorders are accompanied by chronic inflammation (Dela Peña et al., 2005; Henao-Mejia et al., 2012; Esser et al., 2014). Serum levels of proinflammatory cytokines such as TNF- $\alpha$ and IL1B are elevated in cows with ketosis (Zhang et al., 2016; El-Deeb and El-Bahr, 2017). Thus, data from the present study confirmed that ketosis is associated with systemic in- 

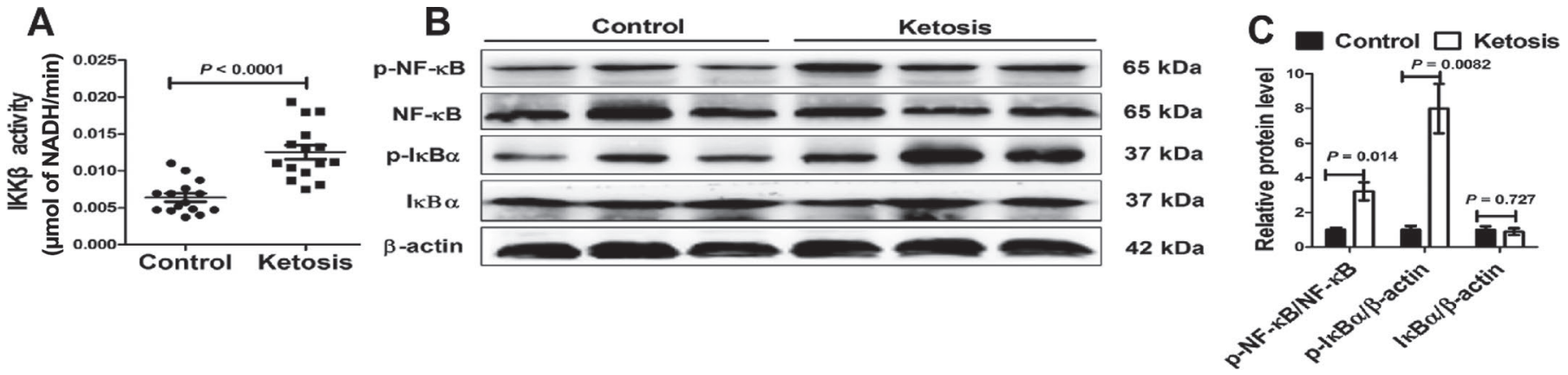

Figure 3. The expression of nuclear factor (NF)- $\kappa$ B signaling proteins and activity of inhibitor of NF- $\kappa B$ (IKK $\beta$ ). (A) Hepatic IKK $\beta$ activity and (B) expression of NF- $\kappa$ B signaling proteins in control cows $(\mathrm{n}=15)$ and dairy cows with ketosis $(\mathrm{n}=15)$. Representative blots are shown.

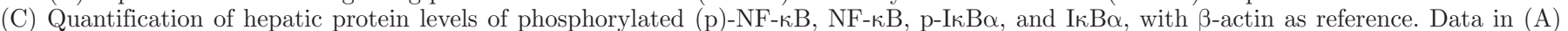
were analyzed with Wilcoxon signed-rank test and expressed as mean \pm SEM; data in $\mathrm{C}$ were analyzed with paired $t$-tests and expressed as the mean \pm SEM.

flammation and overactivation of hepatic NF- $\kappa \mathrm{B}$ and NLRP3 inflammasome signaling, potentially contributing to liver damage and steatosis.

In human and mouse, a clear link exists between NF$\kappa \mathrm{B}$ signaling and fatty liver, and some evidence in cows suggests that this pathway may be relevant to the development of ketosis (Ribeiro et al., 2004; Dela Peña et al., 2005; Li et al., 2015). Thus, the greater phosphory-

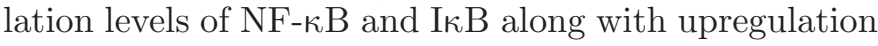
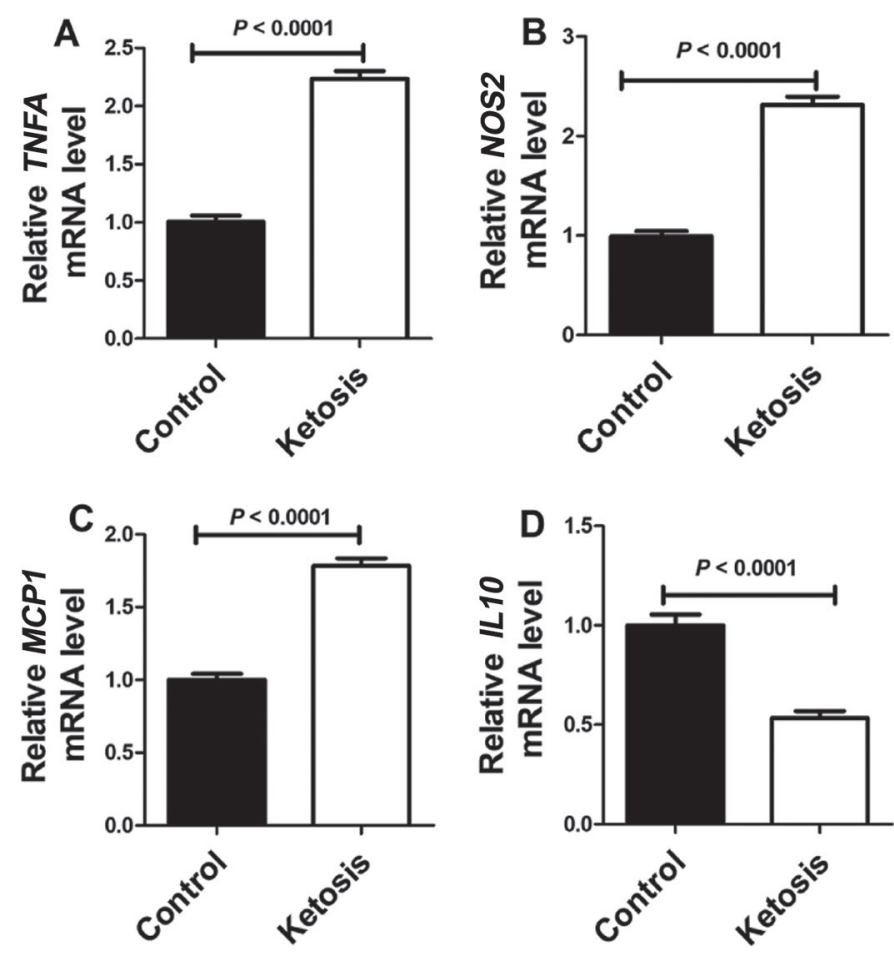

Figure 4. Relative hepatic mRNA expression of inflammatory cytokines TNFA (A), NOS2 (B), MCP1 (C), and IL10 (D) in control cows $(\mathrm{n}=15)$ and dairy cows with ketosis $(\mathrm{n}=15)$. Data were analyzed with paired $t$-tests and expressed as the mean \pm SEM. of MCP1, NOS2, and TNFA, downstream targets of the $\mathrm{NF}-\kappa \mathrm{B}$ signaling, are evidence that the hepatic NF- $\kappa \mathrm{B}$ signaling pathway was overactivated during ketosis and might have played a role in the development of $\mathrm{TG}$ accumulation (Liedtke and Trautwein, 2012; Van Beek et al., 2012).

Previous data underscored the fact that exposure of hepatocytes to high levels of fatty acids and BHB could induce NF- $\kappa \mathrm{B}$ signaling and upregulation of TNF- $\alpha$ synthesis (Shi et al., 2014, 2015). In turn, TNF- $\alpha$ and IL1B can further activate the NF- $\kappa \mathrm{B}$ inflammation pathway (Liedtke and Trautwein, 2012; Van Beek et al., 2012). Taken together, we speculate that the high levels of fatty acids and proinflammatory cytokines all contributed to hepatic NF- $\kappa \mathrm{B}$ signaling overactivation during ketosis.

An activation of NF- $\kappa \mathrm{B}$ signaling could induce the priming step of NLRP3 inflammasome leading to upregulation of $N L R P 3, I L 18$, and $I L 1 B$ (Esser et al., 2014) and oligomerization of the NLRP3 complex and CASP1 activation (Shao et al., 2015). Activated CASP1, in turn, cleaves pro-IL1B and pro-IL18 into their mature forms: IL1B and IL18 (Jo et al., 2016). Thus, the greater activity of CASP1 and upregulation of hepatic $I L 1 B$ and $I L 18$ mRNA in the present study are suggestive of hepatic NLRP3 inflammasome overactivation during ketosis.

In nonruminants, palmitic acid but not oleic acid induces activation of the NLRP3 inflammasome, causing IL1B and IL18 production from immune cells (Wen et al., 2011). Murine hepatocytes also undergo activation of the NLRP3 inflammasome in response to a greater supply of palmitic acid (Yang et al., 2016). The concentration of reactive oxygen species is an efficient activator of NLRP3 inflammasome, and the fact that excessive concentrations of fatty acids impair mitochondrial function underscores the linkages between excessive 


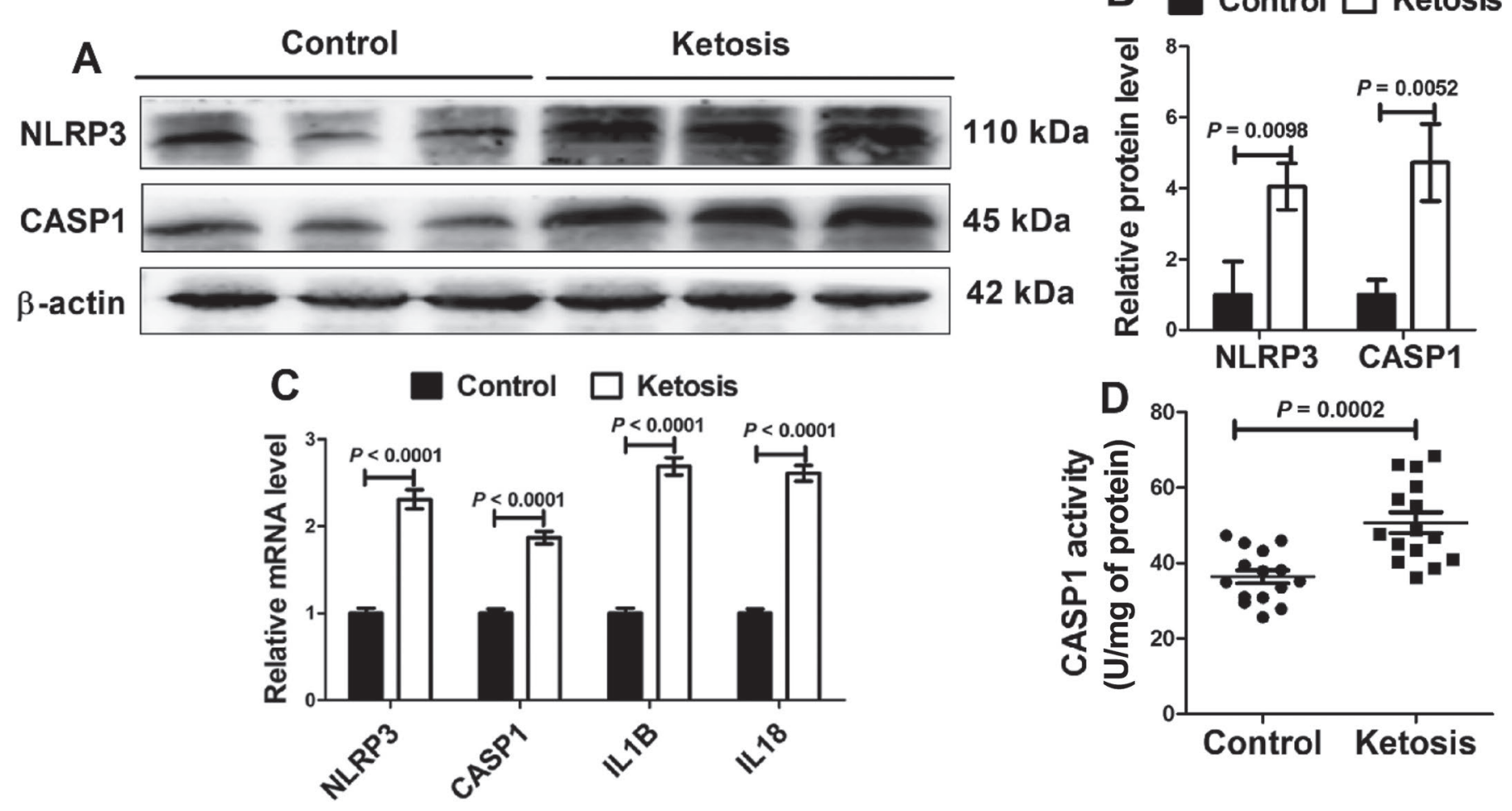

Figure 5. The mRNA and protein levels of NLR family pyrin domain containing 3 (NLRP3) inflammasome and the activity of caspase-1 (CASP1). (A) Hepatic protein levels of NLRP3 and CASP1 in control cows $(\mathrm{n}=15)$ and dairy cows with ketosis $(\mathrm{n}=15)$. Representative blots are shown. (B) Quantification of hepatic protein levels of NLRP3 and CASP1. (C) Relative hepatic mRNA expression of NLRP3, CASP1, IL18, and $I L 1 B$ in control cows $(\mathrm{n}=15)$ and dairy cows with ketosis $(\mathrm{n}=15)$. (D) Activity of CASP1 in control cows $(\mathrm{n}=15)$ and dairy cows with ketosis $(\mathrm{n}=15)$. Data in $(\mathrm{B})$ and $(\mathrm{C})$ were analyzed with paired $t$-tests and expressed as the mean $\pm \mathrm{SEM}$; data in $(\mathrm{D})$ were analyzed with Wilcoxon signed-rank test and expressed as the mean \pm SEM.

lipolysis after calving and susceptibility for NLRP3 activation in the liver (McKeegan and Sturmey, 2011; Lee et al., 2013; Putman et al., 2018). Clearly, the present data reveal a complex cascade of events that triggers hepatic NLRP3 inflammation with a consequent lipotoxic effect and accumulation of TG.

Besides compromising lipid metabolism in the liver, data from the mouse indicate that activation of NF- $\kappa B$ signaling and NLRP3 inflammasome along with high levels of TNF- $\alpha$ could impair hepatic insulin sensitivity and contribute to lipid accumulation (Ham et al., 2016). A direct link between NLRP3 inflammasome, NF- $\kappa \mathrm{B}$ pathway, and altered liver metabolism has been reported in the context of high-fat feeding; that is, silencing of these pathways abrogates the negative effects of high dietary fat on hepatic lipid metabolism and insulin sensitivity (Zhao et al., 2017). Although the ruminant liver is not a lipogenic organ under normal conditions (Hanson and Ballard, 1967), evidence indicates that nutrition (Khan et al., 2014) could induce molecular changes in the liver conducive to lipid accumulation. Moreover, Bradford et al. (2009) reported that a higher TNF- $\alpha$ level could result in a lipid meta- bolic disorder in the liver of cows. Thus, we speculated that an increase in the concentration of TNF- $\alpha$ during ketosis could further exacerbate the progression of hepatic lipid accumulation. Taken together, current and previous data indicate that activation of inflammatory pathways exacerbates disorders of hepatic lipid metabolism.

Consistent with previous studies (Bogin et al., 1988; Herdt, 2000; Du et al., 2017a), the greater blood levels of ALT and AST, indicators of liver damage, confirmed the existence of liver injury during ketosis. Hepatic injury can result in fatty acid-induced lipotoxicity, which accelerates hepatocyte death (Cazanave and Gores, 2010; Du et al., 2017b). At least in mice, overt inflammation can cause liver injury; for example, $T N F-\alpha$ and IL1B produced during activation of the NF- $\kappa \mathrm{B}$ and NLRP3 signaling pathways can lead to mitogenactivated protein kinase (MAPK) apoptosis (Wang et al., 2009). There is evidence that hepatic apoptosis rate via MAPK activation is greater in ketotic liver (Du et al., 2017b). From a mechanistic standpoint, there is a

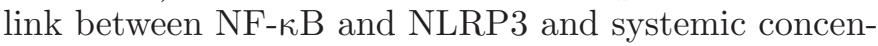
trations of ALT and AST. In rodents, knockdown of 
NF- $\kappa \mathrm{B}$ and NLRP3 was associated with a decrease in blood concentrations of ALT and AST during feeding of high fat diets or diets deficient in methionine-choline (Henao-Mejia et al., 2012). Therefore, our data and that of previous studies indicate that overactivation of NF- $\kappa \mathrm{B}$ and NLRP3 signaling pathway partly mediated and aggravated the pathological injury of the liver in ketotic cows.

\section{CONCLUSIONS}

The hepatic NF- $\mathrm{B}$ signaling pathway and NLRP3 inflammasome are overactivated in ketotic cows and contribute to hepatic injury and lipid accumulation. Accordingly, these pathways have important implications in the context of lipidosis. They represent a target for potential therapeutic applications in the field of periparturient cow management.

\section{ACKNOWLEDGMENTS}

This work was supported by the National Key Research and Development Program (Beijing, China; grant no. 2016YFD0501206), the National Natural Science Foundation of China (Beijing, China; grant no. 31572581, 31672621, and 31772810), the Jilin Natural Science Foundation (Changchun, China; grant no. 20170101148JC), and the Talents Cultivation Program of Jilin University. The authors declare no competing financial interests.

\section{REFERENCES}

Abuajamieh, M., S. K. Kvidera, M. V. Fernandez, A. Nayeri, N. C. Upah, E. A. Nolan, S. M. Lei, J. M. DeFrain, H. B. Green, K. M. Schoenberg, W. E. Trout, and L. H. Baumgard. 2016. Inflammatory biomarkers are associated with ketosis in periparturient Holstein cows. Res. Vet. Sci. 109:81-85.

Arkan, M. C., A. L. Hevener, F. R. Greten, S. Maeda, Z. W. Li, J. M. Long, A. Wynshaw-Boris, G. Poli, J. Olefsky, and M. Karin. 2005 IKK- $\beta$ links inflammation to obesity-induced insulin resistance. Nat. Med. 11:191-198

Bobe, G., J. W. Young, and D. C. Beitz. 2004. Invited review: Pathology, etiology, prevention, and treatment of fatty liver in dairy cows. J. Dairy Sci. 87:3105-3124.

Bogin, E., Y. Avidar, M. Merom, S. Soback, and G. Brenner. 1988. Biochemical changes associated with the fatty liver syndrome in cows. J. Comp. Pathol. 98:337-347.

Bradford, B. J., L. K. Mamedova, J. E. Minton, J. S. Drouillard, and B. J. Johnson. 2009. Daily injection of tumor necrosis factor-a increases hepatic triglycerides and alters transcript abundance of metabolic genes in lactating dairy cattle. J. Nutr. 139:1451-1456.

Brodzki, P., A. Brodzki, L. Krakowski, R. Dąbrowski, M. Szczubiał, and M. Bochniarz. 2019. Levels of selected cytokines and acutephase proteins in the serum of dairy cows with cystic ovarian disease and those in follicular and luteal phases of normal ovarian cycle. Res. Vet. Sci. 123:20-25.

Bustin, S. A., V. Benes, J. A. Garson, J. Hellemans, J. Huggett, M. Kubista, R. Mueller, T. Nolan, M. W. Pfaffl, G. L. Shipley, J. Vandesompele, and C. T. Wittwer. 2009. The MIQE guidelines:
Minimum information for publication of quantitative real-time PCR experiments. Clin. Chem. 55:611-622.

Cai, D., M. Yuan, D. F. Frantz, P. A. Melendez, L. Hansen, J. Lee, and S. E. Shoelson. 2005. Local and systemic insulin resistance resulting from hepatic activation of IKK- $\beta$ and NF- $\kappa$ B. Nat. Med. 11:183-190.

Cazanave, S. C., and G. J. Gores. 2010. Mechanisms and clinical implications of hepatocyte lipoapoptosis. Clin. Lipidol. 5:71-85.

Cui, Y., Q. Wang, R. Chang, X. Zhou, and C. Xu. 2019. Intestinal barrier function-non-alcoholic fatty liver disease interactions and possible role of gut microbiota. J. Agric. Food Chem. 67:2754-2762.

De Nardo, D., and E. Latz. 2011. NLRP3 inflammasomes link inflammation and metabolic disease. Trends Immunol. 32:373-379.

Dela Peña, A., I. Leclercq, J. Field, J. George, B. Jones, and G. Farrell. 2005. NF-kappaB activation, rather than TNF, mediates hepatic inflammation in a murine dietary model of steatohepatitis. Gastroenterology 129:1663-1674.

Deng, Q., G. Liu, L. Liu, Y. Zhang, L. Yin, X. Shi, J. Wang, X. Yuan, G. Sun, and Y. Li. 2015. BHBA influences bovine hepatic lipid metabolism via AMPK signaling pathway. J. Cell. Biochem. 116:1070-1079.

Du, X., L. Chen, D. Huang, Z. Peng, C. Zhao, Y. Zhang, Y. Zhu, Z. Wang, X. Li, and G. Liu. 2017a. Elevated apoptosis in the liver of dairy cows with ketosis. Cell. Physiol. Biochem. 43:568-578.

Du, X., T. Shen, H. Wang, X. Qin, D. Xing, Q. Ye, Z. Shi, Z. Fang, Y Zhu, and Y. Yang. 2018b. Adaptations of hepatic lipid metabolism and mitochondria in dairy cows with mild fatty liver. J. Dairy Sci. 101:9544-9558.

Du, X., Z. Shi, Z. Peng, C. Zhao, Y. Zhang, Z. Wang, X. Li, G. Liu, and X. Li. 2017b. Acetoacetate induces hepatocytes apoptosis by the ROS-mediated MAPKs pathway in ketotic cows. J. Cell. Physiol. 232:3296-3308.

Du, X., Y. Zhu, Z. Peng, Y. Cui, Q. Zhang, Z. Shi, Y. Guan, X. Sha, T. Shen, and Y. Yang. 2018a. High concentrations of fatty acids and $\beta$-hydroxybutyrate impair the growth hormone-mediated hepatic JAK2-STAT5 pathway in clinically ketotic cows. J. Dairy Sci. 101:3476-3487

El-Deeb, W. M., and S. M. El-Bahr. 2017. Biomarkers of ketosis in dairy cows at postparturient period: Acute phase proteins and pro-inflammatory cytokines. Vet. Arh. 87:431-440.

Ertunc, M. E., and G. S. Hotamisligil. 2016. Lipid signaling and lipotoxicity in metabolic inflammation: Indications for metabolic disease pathogenesis and treatment. J. Lipid Res. 57:2099-2114.

Esser, N., S. Legrand-Poels, J. Piette, A. J. Scheen, and N. Paquot. 2014. Inflammation as a link between obesity, metabolic syndrome and type 2 diabetes. Diabetes Res. Clin. Pract. 105:141-150.

Farrell, G. C., and C. Z. Larter. 2006. Nonalcoholic fatty liver disease: From steatosis to cirrhosis. Hepatology 43:S99-S112.

Graber, M., S. Kohler, T. Kaufmann, M. Doherr, R. Bruckmaier, and H. A. van Dorland. 2010. A field study on characteristics and diversity of gene expression in the liver of dairy cows during the transition period. J. Dairy Sci. 93:5200-5215.

Ham, J. R., H. I. Lee, R. Y. Choi, M. O. Sim, K. I. Seo, and M. K. Lee. 2016. Anti-steatotic and anti-inflammatory roles of syringic acid in high-fat diet-induced obese mice. Food Funct. 7:689-697.

Hanson, R. W., and F. J. Ballard. 1967. The relative significance of acetate and glucose as precursors for lipid synthesis in liver and adipose tissue from ruminants. Biochem. J. 105:529-536.

Henao-Mejia, J., E. Elinav, C. Jin, L. Hao, W. Z. Mehal, T. Strowig, C. A. Thaiss, A. L. Kau, S. C. Eisenbarth, M. J. Jurczak, J. P. Camporez, G. I. Shulman, J. I. Gordon, H. M. Hoffman, and R. A. Flavell. 2012. Inflammasome-mediated dysbiosis regulates progression of NAFLD and obesity. Nature 482:179-185.

Herdt, T. H. 2000. Ruminant adaptation to negative energy balance: Influences on the etiology of ketosis and fatty liver. Vet. Clin. North Am. Food Anim. Pract. 16:215-230.

Jo, E. K., J. K. Kim, D. M. Shin, and C. Sasakawa. 2016. Molecular mechanisms regulating NLRP3 inflammasome activation. Cell. Mol. Immunol. 13:148-159.

Khan, M. J., C. B. Jacometo, D. E. Graugnard, M. N. Corrêa, E. Schmitt, F. Cardoso, and J. J. Loor. 2014. Overfeeding dairy cattle 
during late-pregnancy alters hepatic PPAR $\alpha$-regulated pathways including hepatokines: Impact on metabolism and peripheral insulin sensitivity. Gene Regul. Syst. Bio. 8:97-111.

Komatsu, T., F. Itoh, S. Kushibiki, and K. Hodate. 2005. Changes in gene expression of glucose transporters in lactating and nonlactating cows. J. Anim. Sci. 83:557-564.

Kubista, M., J. M. Andrade, M. Bengtsson, A. Forootan, J. Jonák, K. Lind, R. Sindelka, R. Sjöback, B. Sjögreen, and L. Strömbom. 2006. The real-time polymerase chain reaction. Mol. Aspects Med. $27: 95-125$.

Lee, H. M., J. J. Kim, H. J. Kim, M. Shong, B. J. Ku, and E. K. Jo. 2013. Upregulated NLRP3 inflammasome activation in patients with type 2 diabetes. Diabetes 62:194-204.

Li, X., W. Huang, J. Gu, X. Du, L. Lei, X. Yuan, G. Sun, Z. Wang, X. Li, and G. Liu. 2015. SREBP-1c overactivates ROS-mediated hepatic NF- $\mathrm{B}$ inflammatory pathway in dairy cows with fatty liver. Cell. Signal. 27:2099-2109.

Liedtke, C., and C. Trautwein. 2012. The role of TNF and Fas dependent signaling in animal models of inflammatory liver injury and liver cancer. Eur. J. Cell Biol. 91:582-589.

Loor, J. J., G. Bertoni, A. Hosseini, J. R. Roche, and E. Trevisi. 2013. Functional welfare - Using biochemical and molecular technologies to understand better the welfare state of peripartal dairy cattle. Anim. Reprod. Sci. 53:931-953.

McArt, J. A. A., D. V. Nydam, and G. R. Oetzel. 2012. Epidemiology of subclinical ketosis in early lactation dairy cattle. J. Dairy Sci. 95:5056-5066.

McKeegan, P. J., and R. G. Sturmey. 2011. The role of fatty acids in oocyte and early embryo development. Reprod. Fertil. Dev. 24:59-67.

Meng, Y., M. Pan, B. Zheng, Y. Chen, W. Li, Q. Yang, Z. Zheng, N. Sun, Y. Zhang, and X. Li. 2019. Autophagy attenuates angiotensin II-induced pulmonary fibrosis by inhibiting redox imbalance-mediated NOD-like receptor family pyrin domain containing 3 inflammasome activation. Antioxid. Redox Signal. 30:520-541.

Oeckinghaus, A., M. S. Hayden, and S. Ghosh. 2011. Crosstalk in NF$\kappa \mathrm{B}$ signaling pathways. Nat. Immunol. 12:695-708.

Pfaffl, M. W. 2001. A new mathematical model for relative quantification in real-time RT-PCR. Nucleic Acids Res. 29:e45.

Putman, A. K., J. L. Brown, J. C. Gandy, L. Wisnieski, and L. M. Sordillo. 2018. Changes in biomarkers of nutrient metabolism, inflammation, and oxidative stress in dairy cows during the transition into the early dry period. J. Dairy Sci. 101:9350-9359.

Ribeiro, P. S., H. Cortez-Pinto, S. Solá, R. E. Castro, R. M. Ramalho, A. Baptista, M. C. Moura, M. E. Camilo, and C. M. Rodrigues. 2004. Hepatocyte apoptosis, expression of death receptors, and activation of NF- $\mathrm{\kappa B}$ in the liver of nonalcoholic and alcoholic steatohepatitis patients. Am. J. Gastroenterol. 99:1708-1717.

Shao, B. Z., Z. Q. Xu, B. Z. Han, D. F. Su, and C. Liu. 2015. NLRP3 inflammasome and its inhibitors: A review. Front. Pharmacol. $6: 262$

Shi, X., D. Li, Q. Deng, Y. Li, G. Sun, X. Yuan, Y. Song, Z. Wang, X. Li, X. Li, and L. Guowen. 2015. NEFAs activate the oxidative stress-mediated NF- $\kappa \mathrm{B}$ signaling pathway to induce inflammatory response in calf hepatocytes. J. Steroid Biochem. Mol. Biol. 145:103-112

Shi, X., X. Li, D. Li, Y. Li, Y. Song, Q. Deng, J. Wang, Y. Zhang, H. Ding, L. Yin, Y. Zhang, Z. Wang, X. Li, and G. Luo. 2014. $\beta$-Hydroxybutyrate activates the NF- $\kappa \mathrm{B}$ signaling pathway to promote the expression of pro-inflammatory factors in calf hepatocytes. Cell Physiol Biochem. 33:920-932.

Song, Y., X. Li, Y. Li, N. Li, X. Shi, H. Ding, Y. Zhang, X. Li, G. Liu, and Z. Wang. 2014. Non-esterified fatty acids activate the ROS-p38-p53/Nrf2 signaling pathway to induce bovine hepatocyte apoptosis in vitro. Apoptosis 19:984-997.

Stienstra, R., J. A. van Diepen, C. J. Tack, M. H. Zaki, F. L. van de Veerdonk, D. Perera, G. A. Neale, G. J. Hooiveld, A. Hijmans, I.
Vroegrijk, S. van den Berg, J. Romijn, P. C. Rensen, L. A. Joosten, M. G. Netea, and T. D. Kanneganti. 2011. Inflammasome is a central player in the induction of obesity and insulin resistance. Proc. Natl. Acad. Sci. USA 108:15324-15329.

Sun, X., Y. Wang, J. J. Loor, R. Bucktrout, X. Shu, H. Jia, J. Dong, R. Zuo, G. Liu, X. Li, and X. Li. 2019. High expression of cell deathinducing DFFA-like effector a (CIDEA) promotes milk fat content in dairy cows with clinical ketosis. J. Dairy Sci. 102:1682-1692.

Taniguchi, K., and M. Karin. 2018. NF-кB, inflammation, immunity and cancer: Coming of age. Nat. Rev. Immunol. 18:309-324.

Van Beek, M., K. I. Oravecz-Wilson, P. C. Delekta, S. Gu, X. Li, X. Jin, I. J. Apel, K. S. Konkle, Y. Feng, D. H. Teitelbaum, J. Ruland, L. M. McAllister-Lucas, and P. C. Lucas. 2012. Bcl10 links saturated fat overnutrition with hepatocellular NF- $\kappa$ B activation and insulin resistance. Cell Rep. 1:444-452.

Vandanmagsar, B., Y. H. Youm, A. Ravussin, J. E. Galgani, K. Stadler, R. L. Mynatt, E. Ravussin, J. M. Stephens, and V. D Dixit. 2011. The NLRP3 inflammasome instigates obesity-induced inflammation and insulin resistance. Nat. Med. 17:179-188.

Vanholder, T., J. Papen, R. Bemers, G. Vertenten, and A. C. Berge. 2015. Risk factors for subclinical and clinical ketosis and association with production parameters in dairy cows in the Netherlands. J. Dairy Sci. 98:880-888.

Wang, P., W. Qiu, C. Dudgeon, H. Liu, C. Huang, G. Zambetti, J. $\mathrm{Yu}$, and L. Zhang. 2009. PUMA is directly activated by NF- $\kappa \mathrm{B}$ and contributes to TNF- $\alpha$-induced apoptosis. Cell Death Differ. 16:1192-1202.

Wen, H., D. Gris, Y. Lei, S. Jha, L. Zhang, M. T. H. Huang, W. J. Brickey, and J. P. Ting. 2011. Fatty acid-induced NLRP3-ASC inflammasome activation interferes with insulin signaling. Nat. Immunol. 12:408-415.

Xu, C., Q. Xu, Y. Chen, W. Yang, C. Xia, H. Yu, K. Zhu, T. Shen, and Z. Zhang. 2015. The relationship between fibroblast growth factor-21 and characteristic parameters related to energy balance in dairy cows. BMC Vet. Res. 11:271.

Xu, C., Q. Xu, Y. Chen, W. Yang, C. Xia, H. Yu, K. Zhu, T. Shen, and Z. Zhang. 2016. FGF-21: promising biomarker for detecting ketosis in dairy cows. Vet. Res. Commun. 40:49-54.

Yang, G., H. E. Lee, and J. Y. Lee. 2016. A pharmacological inhibitor of NLRP3 inflammasome prevents non-alcoholic fatty liver disease in a mouse model induced by high fat diet. Sci. Rep. 6:26218.

Yang, W., X. Li, G. Liu, H. Zhang, Y. Chen, C. Xia, and C. Xu. 2018. Development of a fatty liver model by restricted feeding of lactating sheep. Acta Sci. Vet. 46:1561.

Zhang, G., D. Hailemariam, E. Dervishi, S. A. Goldansaz, Q. Deng, S. M. Dunn, and B. N. Ametaj. 2016. Dairy cows affected by ketosis show alterations in innate immunity and lipid and carbohydrate metabolism during the dry off period and postpartum. Res. Vet. Sci. 107:246-256

Zhang, Y., X. Li, H. Zhang, Z. Zhao, Z. Peng, Z. Wang, G. Liu, and X. Li. 2018. Non-esterified fatty acids over-activate the TLR2/4NF-Kb signaling pathway to increase inflammatory cytokine synthesis in neutrophils from ketotic cows. Cell. Physiol. Biochem. $48: 827-837$.

Zhao, X. J., Y. Z. Yang, Y. J. Zheng, S. C. Wang, H. M. Gu, Y. Pan, S. J. Wang, H. J. Xu, and L. D. Kong. 2017. Magnesium isoglycyrrhizinate blocks fructose-induced hepatic NF- $\kappa B / N L R P 3$ inflammasome activation and lipid metabolism disorder. Eur. J. Pharmacol. 809:141-150.

Zhong, Z., A. Umemura, E. Sanchez-Lopez, S. Liang, S. Shalapour, J. Wong, F. He, D. Boassa, G. Perkins, S. R. Ali, M. D. McGeough, M. H. Ellisman, E. Seki, A. B. Gustafsson, H. M. Hoffman, M. T. DiazMeco, J. Moscat, and M. Karin. 2016. NF- $\kappa$ B restricts inflammasome activation via elimination of damaged mitochondria. Cell 164:896-910. 